\title{
Legal awareness as a factor to establish entrepreneurship
}

\author{
Jakob B. Drobnik ${ }^{1, *}$ \\ ${ }^{1}$ Poznań University of Technology, Faculty of Engineering Management, Strzelecka 11, Poznań, \\ Poland; Universität Erfurt, Lehrstuhl für Christliche Sozialwissenschaft und Sozialethik, Nordhäuser \\ Str. 63, 99089 Erfurt, Germany.
}

\begin{abstract}
Independent functioning in the economic market appears as a multidimensional task, requiring its participants practical skills as well as, to an ever-greater extent, formal knowledge. It includes knowledge of applicable legal regulations, required in the economic sector, which is approved by the participant. The ability to use legal knowledge quickly turns out to be one of those factors that are of significant progressive or regressive importance for the functioning of the entrepreneur and his business. This publication focuses on research on the meaning and dependence of legal regulations for entrepreneurship education. The point of gravity is the empirical analysis of the universality of legal knowledge and its impact on shaping entrepreneurial attitudes as well as functioning on the economic market.
\end{abstract}

\section{Introduction}

\subsection{Research subject}

Occurrence on the economic market is connected with the necessity to fulfill a number of formal and legal conditions imposed by national legislation, and to an ever greater extent international law, such as European Union regulations, which become an internal part of the national order. This complex dependence between effective functioning on the market and a number of factual and formal factors, as well as useful knowledge has already been noticed by Douglass C. North[1], who commented on it in a dependency scheme: beliefs $\rightarrow$ institutions $\rightarrow$ organizations $\rightarrow$ policies $\rightarrow$ outcomes. And it is the spheres of the institutions and, above all, the policies that formulate binding and comprehensive legal obligations. It follows that both on the part of the entity preparing to implement its business idea, the entity being at the stage of starting business activity and entities already operating on the market, next to practical skills resulting from the specifics of the indented economic sphere, it becomes necessary, even in a basic scope, to have legal knowledge of civil law matters, e.g. contracting, as well as specialist knowledge, proper to a given sphere of economy. These requirements may take the form of a character that can be described as absolute-exclusion and relative-conditioning.

*Corresponding author: jakub.drobnik@put.poznan.pl / jakob.drobnik@,uni-erfurt.de 
In the form of absolute-exclusion-requirements, there are legal regulations that make satisfying conditions the conduct of a given type of economic activity, or the implementation of a specific product, its legal protection, brand protection, the possibility of concluding contracts, liability issues etc. We include formal requirements for the registration of a specific form of running a business, all kinds of restrictions, i.e. licenses, permits, concessions, etc. An example illustrating these requirements is even the need to obtain a license for the generation, processing, storage, transmission, distribution and trade of fuels and energy, or a Community license for international commercial carriage of goods by road. In so far as the reading of the absolute-exclusion-requirements for starting or running a given business activity is not a constitutive barrier at present, whether through a wide access to the Internet, where these requirements are strictly concretised or through wide access to professional legal assistance, provided by a number of law firms. It is different in the case of relatively-conditioning-requirements. Under this term, you can comment on the general knowledge of legal regulations regarding either contracting or liability, as well as other legal areas specific to a particular type of business.

The above-mentioned nomenclature therefore includes a certain amount of knowledge at the elementary level, concerning the rights and obligations of the contracting parties, orders and prohibitions concerning a particular type of contracts, opportunities for the entrepreneur, as well as consequences resulting from their observance or overrunning. In Roman legislation for this type of rationing a solution was found in the form of the principle ignorantia iuris nocet. It was an expression of far-reaching freedom of contracting, but also, and in the first place, drew attention to the consequences of the freedom to contract, i.e. the responsibility for contractual constructions. And although in today's legal regulations, this rule meets with a number of exemptions [2] (in Polish Law resulting even from art. 64 of the Civil Code), its general character has been preserved. Relatively-conditioning-requirements are therefore nothing but knowledge of legal regulation (legal consciousness), that is, some kind of contracting entities operating in the economic market, to form a contract between them in any lawful manner.

\subsection{Methodology}

As part of clarifying the practical aspects of academic didactics, in mid-2018 it was carried out among 267 students of Poznan University of Technology, Poznan University of Economics, also a survey among 42 entrepreneurs, with an empirical analysis of the existence of the relationship between legal consciousness and shaping entrepreneurial attitudes. Among the surveyed students, one can distinguish a group of those who previously took legal education - $131(\approx 49 \%)$, and those who did not take it. The group of surveyed entrepreneurs was used to confront the results obtained from the students' questionnaire and its assessment from a practical point of view.

Most of the respondents came from the Poznan University of Technology, from different fields of study and their different years. Therefore, when drawing general conclusions about students or students in Poland, an estimate of the respondents' faction indicating a given response should be accepted at the level of at least half of the confidence interval (confidence level $=0.99$ and significance $=0.01$ ), assuming that usually the question is 4 responses and each has a selection probability $=0.25$ ):

$$
\mathrm{Z} \sqrt{\frac{0,25 \cdot(1-0,25)}{\mathrm{n}}}=2,59 \sqrt{\frac{0,25 \cdot 0,75}{262}} \cong 0,07
$$

Where: 
$\mathrm{z}$ - the right-handed realization from the standardized normal distribution corresponding to the given 2-level significance level;

$\mathrm{n}$ - a typical number of respondents answering a given question.

Therefore, the inference error is at least $7 \mathrm{pp}$ (percentage points) for the results obtained.

\subsection{Research assumptions}

The research chose a thesis, according to which the knowledge of formal and legal requirements concerning the absolutely-exclusive-requirements for starting and running a business activity is to constitute a small barrier to the industry, while the relativeconditioning-requirements may play a constitutive role. On the basis of this, a hypothesis has been formulated according to which legal problems, which seem to correspond to a broadly understood legal intuition, also understood as a sense of justice, which is in fact the presumption of compliance of the position with the applicable legal status, can be taken without real support for auspicious legal knowledge and, consequently, constitute a significant threat to the functioning of the entrepreneur on the market. Therefore, legal education, even in the basic dimension, seems to be an element contributing to the shaping of entrepreneurship. In this publication, the presented hypothesis will be subjected to empirical analysis based on the results of the conducted statistical survey.

\section{Initial analysis of the research subject}

\subsection{Epistemological aspect of entrepreneurship at the subjective level}

The epistemological analysis at the subjective level was chosen as the starting point of the study of the occurrence of the relationship between legal consciousness and entrepreneurship. At the same time, the attempt to doctrinal unification of entrepreneurial features, presented for example in the works of P. Drucker [3], J. Schumpeter [4] and others [5], was excluded. The surveyed students were left to indicate what at the individual level they identify as entrepreneurial behavior, and what they would identify as conducive to entrepreneurship and its shaping. In addition to clearly emphasizing the importance of various personal predispositions such as creativity, regularity, effectiveness of action, or determination, characterized by an entrepreneurial attitude [6], for almost $73 \%$ of surveyed students, the concept of entrepreneurial behavior goes beyond the genuine framework of activity in the economic market and is identified with such skills as solving problem situations, organization of private life and efficient functioning on the labor market or in society. This type of problem presentation shows a certain evolution at the subjective level in the assessment of what is sometimes associated with the entrepreneurial activity. In fact, it boils down to the praxeological character, which oscillates around the ability to deal with problem situations in the private and social spheres, and effective functioning on the market [7]. However, one should not draw any conclusion from the above that the heterogeneity of the understanding of entrepreneurship is blurred. The respondents clearly distinguish the concept of an entrepreneur as a person operating on the economic market, from other activities that are assigned entrepreneurial characteristics and which go beyond the market sphere itself. This dichotomy conditioning the perception of entrepreneurial activity has become the first significant theoretical depiction at the level of the subject chosen from this study. Secondly, the respondents were left to indicate what they would define as conducive to entrepreneurship, its development and also to shape entrepreneurial attitudes. Thus, the center of gravity was on the one hand clearly located on the market aspects and on the other 
side on the behavioral ones. Answers can be categorized in three basic groups, focusing on social (including psychological), political and legal (social) conditions [8]. At the same time, they indicate a subcutaneous inherence between each other, which prevents an explicit segregation of aspects relating only to one of the indicated conditions. Thus, there is symbiosis between the conditions of social, political and legal nature.

For nearly $\approx 67 \%$ of respondents, the determinants of social (psychological) nature are a criterion of crucial importance both for the formation and development of entrepreneurial attitudes [9]. First of all, the implications arising from family relations associated with upbringing are identified with them [10], transfer of values [11] and with relationships to friends [12]. This type of view corresponds to the results obtained from previous research, carried out e.g. by R. Inglehart and W. Baker [13]. It follows that the constitutive link for the development of entrepreneurship are the applied educational models that stimulate or counteract creativity, independence or determination in achieving the set goals [14]. In the second place, social determinants $(\approx 43 \%)$ are understood as a general (often nationalistic) culture conducive to entrepreneurship [15]. This culture is characterized by the approval for independent functioning on the economic market, including by promoting and supporting entrepreneurial attitudes, innovation or the aforementioned creativity [16]. The practical dimension of this is the creation of appropriate structures and mechanisms to facilitate the implementation of business ideas and conducting market activities, for example through access to information or financial programs. On this level, however, the homogeneity of the sphere of culture is exceeded, through its intentional consolidation with the sphere of politics. It results from the necessity to regulate certain rules and norms of behavior on an above-individual level, thus giving them a universally binding character. Here, as invaluable policy tasks, the respondents indicated shaping a favorable climate for entrepreneurship $(\approx 48 \%)$ by forcing appropriate educational and training programs accessible to all $(\approx 53 \%)$, a favorable approach to independent economic initiatives through clear and unambiguous legislation $(\approx 38 \%)$ and administrative openness, expressed in the transparency of control proceedings and limited possibilities of state regulation (17\%).

An appropriate postulate expressed here by the surveyed is to push politics based on the principles of ordoliberalism [17]. It is characterized by far-reaching freedom rights and a subsidiary role of the state [18]. This regulatory activity of the state is primarily aimed at protecting the freedoms of individuals against the temptations to restrict it (by different authorities), and in economic relations interferes only in so far to the extent that the parties cannot regulate them themselves (or for interference), or if the good of the whole community requires it [19]. The term "good of the whole community" should not, by any means, be ascribed to a generalizing form with pathetic characters, but it will be based on objective criteria, subject to quantitative and quality verification. The supreme rule should also be assumed that all state interference must be exceptional. This model not only favors the shaping and development of entrepreneurship, but also prudent decision making with all responsibility for the consequences arising from them [20]. In the center there is a free market, which is the basis for the economic development of the state and the prosperity of its citizens.

\subsection{Assessment of state interference in running a business on the example of Poland}

With this type of assumptions, it is not surprising that in post-Soviet countries, indoctrinated with planned and centralized economy, citizens' own initiatives are often interpreted as harmful and even anti-state activities. Therefore, the state tries not only to limit the freedom of economic activity of its citizens, but also to create an extensive and as a consequence, non-transparent administrative and legal way, which will allow it as far as 
possible interference in the market activity of individuals, taking the form of decisionmaking and constitutive character. Conducting surveys for most of Polish-language students, as many as $\approx 61 \%$ of them recognized the interference of state authorities in economic relations and the free market as too far-reaching and hampering economic development [21]. $\approx 17 \%$ of the students surveyed considered public activity to be harmful. The remaining part, i.e. $\approx 22 \%$, did not have an opinion on this subject.

It seems to be different in the case of the entrepreneurs surveyed. Among them, up to $\approx 74 \%$ consider the far-reaching interference of the state in the free market as detrimental to business activity, such as the shaping and development of entrepreneurship. Some of them underlined expressis verbis that the regulations introduced in recent years in Poland are of a destructive nature for business. To justify their position, the respondents gave, for example, the lack of transparency of the tax system, excessive length and arbitrariness of administrative and control proceedings as well as rapidly changing legal regulations [22], as well as high costs of running a business, caused by state legislature. Only $\approx 26 \%$ of the surveyed entrepreneurs recognized state interference in the free market as too far-reaching. From the above, at least two conclusions can be drawn:

(1) The majority of respondents recognized that the intervention of the (Polish) state in the free market is too far-reaching and, consequently, unfavorable for running business activity, as well as shaping and developing entrepreneurship. The extensive tax system, numerous and rapidly changing legal regulations rather inhibit than they contribute to economic development, and thus to the development of the state and prosperity of citizens.

(2) Secondly, the assessment of the impact of the state regulatory activity on the free market is fundamentally changing for entrepreneurs, i.e. persons running a business. In this case, the vast majority negatively assess the far-reaching interference of the state with the economy, directly considering it as harmful and even destructive.

The picture emerging from the conducted study clearly indicates that the exorbitant interference of the state in the free market meets with a definite disapproval as limiting economic activity and, consequently, limiting the freedom of citizens. It is unfavorable for conducting market activity and shaping and promoting entrepreneurship. In the case of legal amendments introduced in Poland in recent years, such an assessment results mainly from the meanders of legal regulations, causing the uncertainty of the enterprise on the market, as well as its discretion from the entropy of administrative decisions [23].

\section{The ratio of knowledge of legal regulations to entrepreneurship}

\subsection{The ratio of legal intuition to legal certainty}

Every participation in economic turnover requires its participants to have a basic knowledge base [24], including their rights and mutual obligations. To a large extent, it takes on an aposterioric or intuitive character, resulting from the widespread experience of contracting (e.g. acquisition of goods) and is guided by widely understood common sense. The basic assumption is the presumption of a certain stability of legal regulations and the rationality of the legislator. Based on the above research, the work hypothesis emerged that contractors are more likely to incur contractual obligations, which are included in the preliminary analysis of sui generis health-rational or resulting from their legal intuition (sense of justice), rather than in the case of more comprehensive matter, referring to specific legal knowledge.

Considering the above, the conducted legal awareness surveys of the surveyed students included both potentially simple questions, prima facie appealing to common sense and 
sense of justice. In addition, more complex questions were included, referring to the matter that goes beyond the scope of common experience, requiring professional and reliable knowledge. Sample questions illustrating the complexity of the issues studied are illustrated by the following tables:

Table 1. Respondent declarations: On his property the owner is allowed:

\begin{tabular}{|l|l|c|c|}
\hline & \multicolumn{1}{|c|}{} & Frequency & Percent \\
\hline Valid & Uses your property as he pleases, regardless of neighbors & 4 & 1,5 \\
\hline & $\begin{array}{l}\text { Must refrain from actions that disrupted the use of } \\
\text { neighboring properties }\end{array}$ & 193 & 72,3 \\
\hline & I don't know what's allowed and what's not & 4 & 1,5 \\
\hline & $\begin{array}{l}\text { He's allowed to do everything what's legal, even if he } \\
\text { disrupts the use of neighboring properties }\end{array}$ & 63 & 23,2 \\
\hline & Don't understand the question & 3 & 1,1 \\
\hline Total & & 266 & 99,6 \\
\hline Missing & & 1 & 0,4 \\
\hline Total & & 267 & 100 \\
\hline
\end{tabular}

Source: own research

From the above table, it appears exemplarily that most of the students surveyed understand the legitimacy of limitation in the exercise of ownership rights, resulting from social and socio-economic co-existence of the destination of real estate - and accepts them. At the same time, it clearly shows that the main difficulty for the surveyed students in the above question was the interpretation of the difference between exercising their rights in a lawful manner, but limiting the use of neighboring properties, and such use that will not interfere with the use of neighboring properties. As follows from the subsequent analysis, the aporetic point was the interpretation of the wording "in accordance with the law," or more strictly, the interpretation of the use of real estate that is contrary to the law. The vast majority of the surveyed students, referring to the internal legal intuition or sense of justice, decided that the use that would disrupt the use of other people from their property would be ipso facto illegal.

Table 2. Respondent declarations: If you accidentally receive a money transfer on your account then:

\begin{tabular}{|l|l|c|c|}
\hline & & Frequency & Percent \\
\hline Valid & You can keep it & 69 & 25,8 \\
\cline { 2 - 4 } & You have to return the amount including interest & 76 & 28,5 \\
\cline { 2 - 4 } & $\begin{array}{l}\text { You have to return the amount received, but you're } \\
\text { allowed to keep the interest }\end{array}$ & 67 & 25,1 \\
\cline { 2 - 4 } & Don't know & 54 & 20,2 \\
\hline Total & & 266 & 99,6 \\
\hline Missing & & 1 & 0,4 \\
\hline Total & & 267 & 100,0 \\
\hline
\end{tabular}

Source: own research

When examining the potentially less obvious problem, the basic discrepancy between the generally understood legal intuition and the acquired knowledge comes to light. As in the case of Table 1., you can try to generate and justify the answer by referring to the internal sense of justice or expectations about the functioning of the rules of social coexistence found on Kant's categorical imperative [25], in the case of matter going beyond this range, used in the example of Table 2., the answer is deprived of the presumption of 
justice. In this case, it will based on a specific legal knowledge, which will have the character of acquired knowledge.

At the same time, the spread of responses in Table 2. clearly shows that the surveyed students deprived of the possibility of referring to this legal intuition (or sense of justice) were more inclined to admit the inability to provide an unambiguous answer. Moreover - on the basis of the following responses of respondents granted during the survey, it can be concluded that in the case of a more comprehensive legal matter that cannot be - even if the intention is based on the said intuition, the surveyed students would be more willing to take advantage of professional legal advice rather than in the case of potentially obvious matter, which can be justified by reference to internal and more or less uncertain legal intuition or sense of justice.

The occurrence of the above relationship between the increased readiness for interaction in the event of potentially occurring possibility of referring to the common sense of justice or legal intuition, and the matter going beyond its scope, where the respondents showed greater restraint when taking a definitive position, also came out to be confirmed in the case of other questions such as how: (a) Can I propose other terms (conditions) than I have been offered by the other party when I receive a contract?; (b) If your contractor is late in paying the invoice, and the contract does not state that in the case of delay interest for late payment should be due - are interest included, and if so which? or (c) If another person forces you to sign the contract under the threat of harming you or another person close to you - does the contract have legal effects?

Without going any further into a comprehensive analysis of the direction of the answers given (which remains a different study), the respondents, similarly to the cases set out in Table 1. and Table 2. were more inclined to formulate clear positions when there was the possibility of basing themselves on justice or intuition. compared to cases where this type of possibility was at least limited.

The above sui generis tendency to rely on the internal sense of justice or legal intuition, rather than on the acquired knowledge, clearly showed the fundamental difference as to the surveyed students who took prior legal education (in any scope) or practically encountered the complexity of the problem legal entities in the field of running a business, and those who did not show any prior legal education. Respondents who received legal education statically in $\approx 62 \%$ preferred not to take a definite position on legal issues, which they were uncertain of, rather than rely on their legal intuition. In turn, the respondents who did not receive prior legal education did not see any contraindications. This is clearly seen in the example of Table 3.

Table 3. Respondent declarations: Being a partner in a Ltd

\begin{tabular}{|l|l|c|c|}
\hline \multirow{5}{*}{ Valid } & \multicolumn{1}{|c|}{} & Frequency & Percent \\
\cline { 2 - 4 } & $\begin{array}{l}\text { I am jointly and severally liable for the } \\
\text { company's obligations }\end{array}$ & 89 & 33,3 \\
\cline { 2 - 4 } & $\begin{array}{l}\text { as a rule, I am not responsible for the company's } \\
\text { obligations }\end{array}$ & 113 & 42,3 \\
\cline { 2 - 4 } & I don't know & 37 & 13,9 \\
\cline { 2 - 4 } & I don't know what solidary responsibility means & 16 & 6,0 \\
\hline & I don't understand the question & 6 & 2,2 \\
\hline Total & & 263 & 98,5 \\
\hline Missing & & 267 & 1,5 \\
\hline Total & & & 100,0 \\
\hline
\end{tabular}

Source: own research

Out of the 131 respondents who had previously participated in legal education, 96 $(73.3 \%)$ gave the correct answer, i.e. answer 2 to the question asked, which is in turn almost $85 \%$ of correctly answered answers. $21(\approx 16.0 \%)$ of those in the group of respondents gave 
an incorrect answer, and $14(\approx 10.7 \%)$ of people stated that they do not know the answer to the question indicated in Table 3. Considering other questions posed to the surveyed during the survey, an image is drawn up according to which people who previously supported legal education (in any respect) take a relatively more reserved position in legal matters than people who did not receive legal education. Indeed, it is a somewhat surprising relationship.

A summary analysis of responses provided by students shows that legal awareness is first identified with the possession of certain rights and obligations (closer to the undefined ones) subject to protection. Their execution is subject to most of respect, based on an assessment based on a sense of justice or internal legal intuition, rather than objective criteria stemming from acquired knowledge. This type of dependency can have far-reaching consequences for the development of entrepreneurship and running a business.

\subsection{Practical ratio to comprehensive legal regulations}

Just like the formulation of an unambiguous claim or taking a definite position in the case of problems potentially located in a sense of justice, ergo internal legal intuition, it was easier for the surveyed students, in the case of a more comprehensive regulation requiring specialist knowledge, more willing to use the knowledge of professionals (that is, lawyers). The questions in Table 4. illustrate the relationship indicated above.

Table 4. Respondent declarations: To start a company:

\begin{tabular}{|c|c|c|c|}
\hline & & Frequency & Percent \\
\hline \multirow[t]{6}{*}{ Valid } & $\begin{array}{l}\text { I go to a lawyer to ask for advice on how to choose a } \\
\text { company and how to do it }\end{array}$ & 142 & 53,2 \\
\hline & I will commission a company to a lawyer & 12 & 4,5 \\
\hline & $\begin{array}{l}\text { I am looking for a solution on the internet and I follow what I } \\
\text { find there }\end{array}$ & 15 & 5,6 \\
\hline & $\begin{array}{l}\text { I am looking for a solution on the internet and then I go to a } \\
\text { lawyer }\end{array}$ & 50 & 18,7 \\
\hline & I didn't think about it & 32 & 12,0 \\
\hline & I'm not interested in this & 12 & 4,5 \\
\hline Total & & 263 & 98,5 \\
\hline Missing & & 4 & 1,5 \\
\hline Total & & 267 & 100 \\
\hline
\end{tabular}

Source: own research

The analysis of the answers seems to confirm the hypothesis that in the case of complex problems, the surveyed students are more inclined to resort to professional legal assistance than based on their own legal presumption. 53.2\% admit that would prefer to consult a lawyer about the choice of the appropriate form of the company, corresponding to the business activity they intend to do, rather than relying on their own knowledge or information obtained from other sources, e.g. $18.7 \%$ of respondents stated that they would get acquainted with the legal problem in the first place on the internet, and then (if necessary) would go for professional advice to a lawyer in order to verify the previously obtained information. Analyzing the problem presented in Table 4. in a general way, it turns out that $57.7 \%$ of the surveyed students would get advice from a professional, while $18.7 \%$ would seek first advice on the Internet or other sources.

Considering the results of other answers provided by the surveyed students, the absolutely-exclusion-requirements due to their complexity, and hence the requirement to refer to specific regulations or legal proceedings, do not constitute a real barrier to entrepreneurship or entrepreneurial building, and this is paradoxically just because of its 
complexity. Being aware of the need to comply with legal requirements, which are not subject to the presumption of legal knowledge, the surveyed students (this is also confirmed in the case of entrepreneurs) in a large part would immediately seek legal assistance from professional entities.

Interestingly, the relationship shows that among the surveyed students, only those who did not receive prior legal education or did not encounter legal issues at the business level, would be willing to entrust the establishment of a company to a lawyer without any consultation regarding the intentions of business intentions $(4.5 \%)$, or they would try to deal with the problem themselves $(5.6 \%)$. However, these results should be approached with some reserve, as most of the surveyed students came out of a theoretical assumption.

Further analysis of the answers given in the study confirms that where a problem issue arises, no longer existing in the so-called legal intuition or sense of justice of the respondents, then they are more likely to seek legal assistance (be it on the internet or a professional) than react with ad hoc yourself. For the functioning of the enterprise, as well as the implementation of business ideas, it can be of fundamental importance.

\subsection{Dependence of legal awareness in relation to entrepreneurship}

In the theoretical aspect between the entrepreneurship itself, its shaping and legal awareness, there does not appear to be a direct causal relationship. Innovativeness, creativity or determination in achieving the goals set, belong to personal characteristics, the appropriate stimulation of which may result in their progressive development [26]. Knowledge of legal regulations does not seem to play a significant or even any role in this process. Insofar as in the theoretical aspect it is difficult to deny this claim, in practical terms, characterized by the ability to effectively implement their business ideas into life and, above all, in the functioning of the economic market, it can play a decisive role [27].

Extending the research carried out by transferring them to the practical functioning in the economic market, an additional survey was conducted among 42 people running a business. They were asked a few specific questions to find out what role their activities in principle play (1) personal knowledge of legal regulations and (2) legal consultations.

The first question was related to the acquisition of legal education by entrepreneurs before starting to set up their own business. 31 (73.8\%) of people admitted that they did not take any legal education, and $11(\approx 26.2 \%)$ or attended law classes (generally understood) while studying ( 7 people), or independently tried to improve for purposes related to the functioning on the market. $23(\approx 64.8 \%)$ of the entities claimed that both personal knowledge of legal provisions and the use of permanent legal services provided by professional entities are of decisive importance for their operations. As many as 12 $(\approx 28.6 \%)$ of people admitted that without professional legal protection they would no longer function on the economic market, and $7(\approx 16.6 \%)$ of people realized that they played an auxiliary role. $18(\approx 42.9 \%)$ of people admitted that due to lack of legal knowledge and not referring to legal consultations with a professional, they happened to conclude ad hoc an unfavorable contract for their company. $9(\approx 21.4 \%)$ of people did not have to deal with such a situation, $11(\approx 26.2 \%)$ of people stated that from the very beginning they used professional legal services and each consult before the signing with lawyers. $4(\approx 9.6 \%)$ people indicated that they run a business with a lawyer.

Reflecting on the issue of the relationship between entrepreneurship and knowledge of legal regulations, the respondents were asked: Is there an impact of legal regulations on their entrepreneurship, since such relationship has already been established for the functioning of the company? $34(\approx 81 \%)$ stated, that the lack of knowledge of legal regulations or the lack of legal consultations may have a negative impact on shaping and building entrepreneurship, just as it may inhibit or lead to the termination of running a 
business. A significant threat was identified primarily in the motivational dimension (25 people - $\approx 59.5 \%$ ). Unfavorable decisions resulting from the lack of knowledge of legal regulations, taken especially at the very beginning of establishing or running a business, implementing an idea, putting a product on the market, protecting a utility model or obtaining a patent protection of a patent, may contribute to the resignation of further attempts to start a business or to continue it. $6(\approx 14.3 \%)$ postulated that he did not think about this issue, hence it is difficult to give a definitive answer. Only $2(\approx 4.7 \%)$ people indicated that they don't see such a relationship.

It is clear from the above that knowledge of legal regulations plays an important role at the establishment stage and during the functioning of the enterprise. Although it is not connected with the development of entrepreneurship per se, its lack may have a demotivating effect on people wishing to start an independent business activity. A contrario knowledge of legal regulations is not a guarantee of success on the market. It should be rather attributable to the subsidiary character, which in a better way allows to operate on the market by protecting the entrepreneur from making ipso iure unfavorable decisions, the unfavorability of which does not result from the object of contracting itself.

\section{Conclusions}

\subsection{Subject applications}

Effective functioning on the economic market is not only an external expression of entrepreneurship, but to an ever-greater extent the ability to reconcile formal requirements set by changing legal regulations and market demand. Research, whose preliminary results are presented in the pages of this article, focused on the assessment of how knowledge of law can condition or stimulate business activity, and thus affect entrepreneurship. Even the initial subject analysis allowed for differentiation between matter defined as absoluteexcluding-requirements and relative-conditioning-requirements. In matters in which formal legal formal knowledge was required, the fulfillment of which involved the establishment of an independent business, implementation of the invention, obtaining a patent, etc., the respondents eagerly reached for the legal service provided by professionals. In this regard, one can draw the conclusion that in problem-related issues, people are more likely to refer for advice from professional entities than they would seem to be on themselves. In this dimension, the research confirmed the initial thesis that problematic legal issues do not constitute a brake both for running a business or for developing entrepreneurship through its practical implementation.

It is different in cases related to issues referred to as relative-conditioning-requirements. The conducted research confirmed the initial thesis that in legal matters, which were in the individual sense of justice (or legal intuition), the respondents were more inclined to take risks by taking a specific position. The difference between the respondents who took legal education and those who did not experience it was also evident. The first group was more likely to be chastened when taking a definite position regarding legal matters, which resulted from their legal intuition, and did not find support in acquired knowledge. Also, in these cases they would be willing to use legal services provided by professional entities, rather than rely on their own feeling. Meanwhile, the respondents who did not take legal education were more inclined to formulate definitive positions based on their legal intuition and sense of justice, in a legal matter that could potentially fall within this scope.

The causal link between these dependencies and running a business and shaping entrepreneurship has been articulated in fine in the case of the entrepreneurs surveyed. First, it was concluded that the relationship between entrepreneurship and legal 
consciousness refers in fact to the practical and not the theoretical dimension of entrepreneurship. This means that the law per se does not fulfill the condition of stimulating or shaping entrepreneurship. In this sense, the knowledge of legal regulations or legal education does not contribute to its growth, but it is important in terms of realizing your creativity or innovation by implementing a business idea into life and functioning in the economic market. Confirmation of persons conducting business activity found a dependence on the conducted survey among students that people who received legal education are more prudent in formulating definitive positions (in practice this takes the form of assessing the meaning of contractual provisions), rather than people who did not receive such education. This prudence results from the awareness that legal regulations or contractual clauses (or lack thereof) can have consequences that prima facie cannot be seen. Hence, basing on the professional's assessment will be a more beneficial solution than basing only on its own legal intuition or sense of justice. However, this sui generis contractual caution should not be equated with business caution, i.e. functioning on the market (implementation of innovative solutions or inventions in effect) and taking risk. The attribute of entrepreneurship is estimation, but also risk taking, which in the case of doing business seems to be inevitable [28]. Knowledge of legal regulations does not avoid the risk of running a business, but contributes to a better assessment of the business and, consequently, to better functioning on the market.

The study shows that just as knowledge of law, legal education will not directly contribute to creating or shaping entrepreneurship as such, but in fact to build and develop a company, that is, practical implementation of entrepreneurship in life. Hence the conclusion, that dissemination of legal knowledge through appropriate education should be considered as an important factor that will facilitate the practical implementation of entrepreneurship, and thus indirectly affect its development.

\subsection{Educational applications}

Common educational systems focus their attention largely on the general intellectual development of the student, or on the specialization resulting from the chosen field of research. This applies to the primary school, where education is of a general nature, directed at the overall intellectual development of the student, as well as higher education, such as universities, where the point of gravity lies in completing the knowledge and skills of the chosen field of science. Both, in the first and the second case, even general legal education is a rare occurrence. In a sense, it was reserved for law departments whose graduates are to follow professional advice.

Meanwhile, effective functioning on the economic market is associated with the necessity of having a range of skills resulting not only from the chosen specialization, or implementation of a business idea, but also contractual knowledge. Economic practice certifies that it is imperative for entrepreneurs to extend their skills beyond the scope of their business activities to knowledge of legal grounds. This applies not only to people who function independently on the market, but indeed to every adult person.

Therefore, it is necessary to consider introducing comprehensive legal education, taking into account basic knowledge, including civil law, in particular contracting and economic and patent law. It is about providing people entering the market with some general knowledge regarding either contract or formal and legal aspects of setting up and running a business, as well as forms of protection of their property - including intellectual property. Although, indeed, it should not be expected that it will contribute to the growth of entrepreneurship as a certain personality traits, as has been previously pointed out, it can be important for effective functioning in the economic market. Complex problems requiring specialist knowledge will remain the responsibility of professionals. However, even if the 
actual, but not the supposed, knowledge of your rights and obligations, as well as the rights and obligations of the official apparatus, may improve the market

A positive aspect of the introduction of universal legal education is also the contribution to the growth of civic awareness and law. In the case of students of technical directions, this would mean not only acquiring specialist knowledge resulting from the chosen field, but also the skills of practical implementation of their innovativeness in life and its protection.

\section{References}

1. D.C. North: Understanding the Process of Economic Change, Princeton, 155-156 (2005)

2. Cf. A. Booke: When Ignorance of the Law Became an Excuse: Lambert and Its Progeny, American Journal of Criminal Law 19/2, 279-312 (1992)

3. P. Drucker: Innovation and entrepreneurship. Practice and principles, New York, 21-29 (1993)

4. J. Schumpeter: The Theory of Economic Development: An Inquiry into Profits, Capital, Credit, Interest and the Business Cycle, New Brunswick - London 2008, 85-89, 93, 102, 116, 144, 153, 180; A. Ebner: Schumpeterian Entrepreneurship Revisited: Historical Specificity and the Phases of Capitalist Development, Journal of the History of Economic Thought 28/3, 315-332 (2006)

5. Cf. J. Iversen/ R. Jørgensen/ N. Malchow-Møller: Defining and Measuring Entrepreneurship, Boston - Delft 2008, 3-15; L.-P. Dana: Toward a multidisciplinary definition of indigenous entrepreneurship, in: L.-P. Dana/ R.B. Anderson (ed.): International Handbook of Research on Indigenous Entrepreneurship, Cheltenham - Northampton 2007, 3-6; G.T. Lumpkin/ B.B. Lichtenstein: The role of organizational learning in the opportunity-recognition process, Entrepreneurship Theory and Practice 29/4, 451-472 (2005)

6. J.S. McMullen/ L.A. Plummer/ Z.J. Acs: What is an entrepreneurial opportunity?, Small Business Economics 28/4, 273-283 (2007)

7. S. Shane/ S. Venkataraman: The promise of entrepreneurship as a field of research, Academy of Management Review 25/1, 218-219 (2000)

8. The indicated features correspond to the adopted theoretical assumptions: Cf. J. Bessant/ J. Tidd: Innovation and Entrepreneurship, Chichester 2011, 10-12, 155-190; J. Heinonen/ U. Hytti/ P. Stenholm: The role of creativity in opportunity search and business idea creation, Journal of Education and Training 53/8 (2011), 659-672; G. Hills/ G. Lumpkin/ R. Singh: Opportunity recognition: Perceptions and behaviors of entrepreneurs, Wellesley 1997, 203-218; S.Y. Lee/ R. Florida/ Z.J. Acs: Creativity and entrepreneurship: A Regional analysis of new firm formation, Regional Studies 38 (2004), 879-891; N. Nicolaou/ S. Shane: Creative personality, opportunity recognition and the tendency to start businesses. A study of their genetic predispositions, Journal of Business Venturing 30, 407-419 (2015)

9. M.J. Chen/ C. Cunradi: Job stress, burnout and substance use among urban transit operators: The potential mediating role of coping behavior, Work \& Stress 22/4 (2008), 327-340; J. Wincent/ D. Örtqvist: A comprehensive model of entrepreneur role stress antecedents and consequences, Journal of Business and Psychology 24, 225-243 (2009)

10. Cf. Ch. Steyaert/ J. Katz: Reclaiming the space of entrepreneurship in society: Geographical, discursive and social dimensions, Entrepreneurship and Regional Development Vol. 16(3), 179196 (2004)

11. M. Nieto/ N. Gonzalez-Alvarez: Social capital effects on the discovery and exploitation of entrepreneurial opportunities, Int. Entrep. Manag. 12, 507-530 (2016)

12. Cf. I. Ajzen: The Theory of planned behavior, Organizational Behavior and Human Decision Processes 50(2), 179-211 (1991)

13. R. Inglehart: Changing values among western publics from 1970 to 2006, West European Politics 31/1-2, 130-146 (2008)

14. L. Edelman/ H. Yli-Renko: The Impact of Environment and Entrepreneurial Perceptions on Venture-Creation Efforts: Bridging the Discovery and Creation Views of Entrepreneurship, Entrep. Theory Pract. 34, 833-856 (2010)

15. R. Inglehart/ W.E. Baker: Modernization, cultural change, and the persistence of traditional values, American Sociological Review 65(1), 19-51 (2000)

16. B. Sabuhilaki: Social Factors Affecting Entrepreneurship and Youth Employment, IJHCS 3/1 (2016), 1232-1234; J.-U. Martens: Der persönliche Berater. Förderung erfolgsbestimmender 
Einstellungen, in: U. Dittler (ed.): E-Learning. Einsatzkonzepte und Erfolgsfaktoren des Lernens mit interaktiven Medien, Oldenburg - Münschen - Wien , 121-138, (2003)

17. J. Bergman/ H. Brodd: How national values influence entrepreneurial behavior. A case study of India and Sweden, Stockholm School of Economics, 34(43), 38-40, (2014)

18. D. Politis: The process of entrepreneurial learning: A conceptual framework, Entrep. Theory Pract 29, 399-424 (2005)

19. W. Eucken: Grundsätze der Wirtschaftspolitik, Tübingen 1952, 225, 270, 279, 285, 334, 338.

20. O. Höffe: Vernunft und Recht. Bausteine zu einem interkulturellen Rechtsdiskurs, Frankfrut a.M., 220-239 (1996)

21. D.C. North: Institutions, Institutional Change and Economic Performance, Cambridge 1990, 27; Cf. D.C. North: Government and the American Economy. A New History, Chicago, 1-13 (2007)

22. Cf. D. Smallbone/ F. Welter: The role of government in SME development in transition economies, International Small Business Journal 19/4, 63-77 (2001)

23. Cf. M. Smoleń/ E. Górniak: Interwencjonizm państwowy w warunkach rynkowych, Rzeszów, 17 (2007)

24. A.A. Alchian: Uncertainty, evolution and economic theory, Journal of Political Economy 68/3, 211-221 (1950)

25. A. Dobaczewska/ A. Powałowski/ H. Wolska: Nowe prawo przedsiębiorców, Warszawa, 63-66, 105, 119-134, 143-144 (2018)

26. D. Kaźmierczak: Skills and capabilities in the knowledge society, in: E. Smyrnova-Trybulska (ed.): E-Learning Vol. 9. Effective Development of Teachers' skills in the Area of ICT and ELearning, Katowice - Cieszyn, 23-47 (2017)

27. Cf. J. Harrison: Kant's Examples of the First Formulation of the Categorical Imperative and The Categorical Imperative, Ethical Essays 2, 87-99, 100-104; H. Jonas: Das Prinzip Verantwortung. Versuch einer Ethik für die technologische Zivilisation, Frankfurt a.M. 1984, 36-37 (1993)

28. A. Ardichvili/ R. Cardozo/ S. Ray: A theory of entrepreneurial opportunity identification and development, J. Bus. Ventur 18, 105-123 (2003)

29. Cf. S. Shane: Prior knowledge and the discovery of entrepreneurial opportunities, Org. Sci. 11, 448-469 (2000)

30. A.C. Corbett: Learning asymmetries and the discovery of entrepreneurial opportunities, J. Bus. Ventur 22, 97-118; Cf. N.J. KRUEGER/ P.R. DICKSON: How believing in ourselves increases risk taking: Perceived self-efficacy and opportunity recognition, Decis. Sci. 25 (1994), 385-400 (2007) 